\title{
USO DE TESTE DE QUÍMIO-SENSIBILIDADE PARA ESCOLHA DA QUIMIOTERAPIA ADJUVANTE NO CÂNCER GÁSTRICO AVANÇADO
}

\author{
USE OF THE CHEMOSENSITIVITY TEST TO CHOOSE APPROPRIATE ADJUVANT \\ CHEMOTHERAPY FOR ADVANCED GASTRIC CANCER
}

\author{
Wilson Shinjiro Matsuzaki ${ }^{1}$; Francisco César Martins Rodrigues, TCBC-SP'; \\ Carlos Alberto Malheiros, TCBC-SP ${ }^{3}$; Fares Rahal, ECBC-SP ${ }^{4}$
}

\begin{abstract}
RESUMO: Objetivo: Introduzir e familiarizar em nosso meio o uso do teste de químio-sensibilidade MTT avaliando a ação de agentes quimioterápicos sobre células tumorais de 30 doentes com câncer gástrico avançado. Correlacionar os resultados do teste MTT com os aspectos clínicos, anátomo-patológicos e estádio utlizando a mesma metodologia do estudo realizado em pacientes japoneses na Universidade de Keio, Japão. Método: Foi realizado o teste MTT em tumores de 30 pacientes com diagnóstico de adenocarcinoma gástrico, submetidos ao tratamento cirúrgico no Departamento de Cirurgia da Faculdade de Ciências Médicas da Santa Casa de São Paulo. Foram estudados in vitro os seguintes agentes quimioterápicos: mitomicina C, doxorrubicina, cisplatina e 5-fluorouracil. Resultados: Os índices de atividade sobre células tumorais foram: 16,6\% para a mitomicina C, 10,0\% para a doxorrubicina, 6,6\% para a cisplatina e 6,6\% para o 5-fluorouracil. Os resultados do teste MTT não tiveram correlação com a idade, sexo, aspectos microscópicos e estádio $(\mathrm{p}>0,05)$. Conclusão: A ação dos agentes quimioterápicos estudados sobre células tumorais do câncer gástrico foi baixa. Os resultados da ação dos quimioterápicos in vitro não apresentou correlação estatística com a idade, sexo, aspectos microscópicos e estádio destes doentes. Utilizando a mesma metodologia, tanto em nosso meio como em pacientes japoneses, a quimio-sensibilidade se mostrou baixa em ambos os estudos, podendo-se deduzir também que os resultados da químiosensibilidade independe da etnia. Com o surgimento de novos agentes quimioterápicos, a expectativa é grande para melhores resultados na prática clínica. Com a utilização e difusão do teste MTT em nosso meio, poder-se-á criar protocolos e estudos multicêntricos para selecionar os quimioterápicos a serem utlizados (Rev. Col. Bras. Cir. 2006; 33(4): 228-234).
\end{abstract}

Descritores: Neoplasias gástricas; Quimioterapia adjuvante; Adenocarcinoma; Ensaios de seleção de medicamentos antitumorais.

\section{INTRODUÇÃO}

O câncer gástrico permanece como uma importante causa de mortalidade no mundo, apesar do declínio na incidência nas últimas décadas. É o terceiro tumor maligno mais freqüente no mundo, com aproximadamente 870.000 casos novos em 2004. Em homens a incidência é duas vezes maior do que em mulheres ${ }^{1-5}$.

No Brasil, os dados do Instituto Nacional do Câncer de 2005, estimam 15.170 novos casos para os homens e 7.975 casos novos para as mulheres. Constata-se uma diminuição temporal das taxas de mortalidade por este tumor, porém ocupa o segundo lugar, atrás apenas do câncer de pulmão ${ }^{1}$.

Apesar da fase atual de terapêutica multimodal para o tratamento dos tumores do aparelho digestivo, o tratamento cirúrgico continua sendo a base do tratamento para o câncer gástrico ${ }^{6}$.

As terapias complementares, tais como a quimioterapia, imunoterapia e a radioterapia, são utilizadas conforme o estádio evolutivo da doença, como adjuvante ao tratamento cirúrgico após as ressecções, como paliativa nos tumores residuais ou inextirpáveis e na doença disseminada, bem como neo-adjuvante na tentativa de tornar a extirpação possível. O objetivo primordial é aumentar a sobrevivência ao destruir possíveis células tumorais remanescentes ${ }^{7,8}$.

Se por um lado, têm-se realizados estudos para verificar a eficácia da quimioterapia, mesmo com fins paliativos, por outro lado o melhor esquema quimioterápico ainda é objeto de especulações ${ }^{7,8}$.

Entre os atuais agentes quimioterápicos utilizados no câncer gástrico estão o 5-fluorouracil (5-FU), a mitomicina $\mathrm{C}$, as antraciclinas, a cisplatina, o etoposídeo, o metotrexato, os taxanos (docetaxel e paclitaxel) e o irinotecano ${ }^{9}$.

Com o intuito de se poder individualizar a seleção e a resposta de cada doente aos agentes quimioterápicos, surgiram os testes de químio-sensibilidade.

Foram primeiramente descritos na década de 50 e desenvolvidos baseando-se na observação, que tumores histologicamente idênticos freqüentemente diferiam em suas respostas ao tratamento quimioterápico ${ }^{10,11}$

\footnotetext{
1. Mestre em Medicina e Doutorando do Curso de Pós-Graduação em Cirurgia Geral da Faculdade de Ciências Médicas da Santa Casa de São Paulo Bolsista CAPES.

2. Professor Adjunto Doutor do Departamento de Cirurgia da Faculdade de Ciências Médicas da Santa Casa de São Paulo

3. Professor Adjunto Doutor e Chefe do Serviço de Estômago, Duodeno e Obesidade Mórbida do Departamento de Cirurgia da Faculdade de Ciências Médicas da Santa Casa de São Paulo.

4. Professor Titular e Livre-Docente de Clínica Cirúrgica do Departamento de Cirurgia da Faculdade de Ciências Médicas da Santa Casa de São Paulo.

Recebido em 03-02-06

Aceito para publicação em 03-03-06

Conflito de interesses: nenhum

Fonte de financiamento: FAP/CAPES

Trabalho realizado no Departamento de Cirurgia da Faculdade de Ciências Médicas da Santa Casa de São Paulo e no Laboratório de Medicina Molecular do Departamento de Ciências Fisiológicas da Faculdade de Ciências Médicas da Santa Casa de São Paulo.
} 
Os testes de químio-sensibilidade baseiam-se na avaliação em laboratório da ação de agentes quimioterápicos sobre tumores, em especial aqueles com o mesmo tipo histológico de um mesmo órgão ${ }^{12,13}$.

São divididos em testes in vivo, realizados em camundongos geneticamente modificados e in vitro nos quais se fazem a avaliação de cultura de células ou tecidos tumorais em contato com agentes quimioterápicos ${ }^{14}$.

Os testes de químio-sensiblidade mais utilizados atualmente na prática clínica são: o teste MTT ${ }^{13,15,16,17,18}$, referente a sigla do reagente utilizado na avaliação final, ou seja, do 3 (4,5 dimetiltiazol-2yl)-2-5-difenil-2H tetrazolato de bromo (MTT, Sigma, St. Louis, MO); o teste HDRA ${ }^{19-22}$, sigla do teste de resposta da cultura tecidual aos quimioterápicos e o teste $C D$ $\mathrm{DST}^{23}$, sigla de teste de químio-sensibilidade de quimioterápicos embebida em gota de colágeno.

O teste MTT consiste na avaliação colorimétrica, rápida, da atividade de células tumorais. Baseia-se na redução do sal tetrazolato pela enzima hidrogenase succínica presente na mitocôndria da célula tumoral, o qual adquire uma coloração violácea que é avaliada por espectrofotometria. $\mathrm{O}$ método é de custo baixo, obtendo-se resultados em 48 horas $^{13}$. As análises de seu emprego estão descritos na literatura ${ }^{24-33}$.

Este estudo foi baseado em estágio realizado no Departamento de Cirurgia da Faculdade de Medicina da Universidade Keio, em Tóquio, Japão ${ }^{27}$. Os dados obtidos durante o estágio foram utilizados na dissertação de mestrado ${ }^{29}$. O emprego de testes de químio-sensibilidade tem se tornado de uso rotineiro em alguns centros oncológicos no Japão como fator para seleção dos agentes quimioterápicos ${ }^{31}$, porém no Brasil este tema ainda é incipiente.

O presente estudo tem por objetivo introduzir e familiarizar o uso do teste MTT em nosso meio, avaliando a atividade de quimioterápicos, sobre células tumorais de doentes com adenocarcinoma gástrico submetidos ao tratamento cirúrgico, correlacionar os resultados do teste MTT com os aspectos clínicos e anátomo-patológicos dos doentes estudados e com os dados os resultados deste estudo obtidos anteriormente ${ }^{27,29}$.

\section{MÉTODO}

Foram estudados 30 pacientes com câncer gástrico avançado, durante o período de fevereiro a setembro de 2004. Este trabalho foi aprovado pelo Comitê de Ética em Pesquisa em Seres Humanos da Irmandade da Santa Casa de Misericórdia de São Paulo.

A idade variou de 30 a 86 anos (média de 58 anos), sendo 17 do sexo masculino.

Estes pacientes foram submetidos a tratamento cirúrgico de acordo com as normas da Japanese Gastric Cancer Association (JGCA) ${ }^{34}$, que basicamente recomendam gastrectomia sub-total ou total dependendo da localização da lesão no estômago associada a ressecção linfonodal tipo D 2 quando possível.

Dezesseis doentes foram submetidos a gastrectomia sub-total, onze doentes a gastrectomia total, um a laparotomia exploradora, um a degastrectomia e um a gastroentero anastomose. Nestes últimos três doentes foram colhidos materiais para o teste de químio-sensibilidade, de linfonodos metastáticos.

Estabeleceram-se os critérios das características clínicas, bem como dos aspectos microscópicos e estádio do câncer gástrico (Tabela. 1).

O teste de químio-sensibilidade utilizado foi o teste MTT $^{13}$. A sua descrição segue abaixo.

Logo após a ressecção do tumor, cerca de 5 gramas da área tumoral era retirada para a realização de teste de químiosensibilidade. $\mathrm{O}$ fragmento do tumor era colocado imediatamente em tubo de ensaio, em solução de $\mathrm{HANKS}^{\circledR}$, que continha $100 \mathrm{U} / \mathrm{ml}$ de penicilina, $100 \mu \mathrm{g} / \mathrm{ml}$ de estreptomicina e $0,25 \mu \mathrm{g} / \mathrm{ml}$ de anfotericina $\mathrm{B}$.

Após a lavagem do material em câmara de fluxo laminar, a amostra era macerada em pequenos fragmentos.

Em seguida, era submetida ao processo enzimático de degradação a $37,5^{\circ} \mathrm{C}$, utilizando-se solução contendo protease a $0,5 \mu \mathrm{g} / \mathrm{ml}$, colagenase a $0,2 \mu \mathrm{g} / \mathrm{ml}$ e deoxiribonuclease tipo I a $0,2 \mu \mathrm{g} / \mathrm{ml}$ para obtenção de células tumorais. Após 30 minutos o macerado era filtrado, centrifugado a 2.000 rotações por minuto e o sobrenadante eliminado, ficando somente as células tumorais no fundo do tubo de ensaio.

O meio de cultura utilizado foi o RPMI $1640^{\circledR} \mathrm{com}$ $10 \%$ de soro fetal bovino, contendo também $100 \mathrm{U} / \mathrm{ml}$ de penicilina, $100 \mu \mathrm{g} / \mathrm{ml}$ de estreptomicina e $0,25 \mu \mathrm{g} / \mathrm{ml}$ de anfotericina $\mathrm{B}$, para evitar o crescimento de microorganismos.

Após a homogenização com $10 \mathrm{ml}$ do meio de cultura, contavam-se as células viáveis pelo método de coloração com o azul de tripano. A solução obtida era distribuída em microplaca com 96 espaços (16 linhas verticais de oito espaços). Para cada espaço da microplaca utilizou-se a concentração de cerca de 1 x $10^{5}$ células tumorais $/ \mathrm{ml}$.

Tabela 1 - Critérios das características clínicas e dos aspectos microscópicos e estádio do câncer gástrico.

\begin{tabular}{|c|c|}
\hline$\overline{\text { Características }}$ & critérios estudados \\
\hline \multirow[t]{2}{*}{ Idade } & $>70$ anos \\
\hline & $=70$ anos \\
\hline \multirow[t]{2}{*}{ Sexo } & masculino \\
\hline & feminino \\
\hline \multirow[t]{2}{*}{ Diferenciação histológica } & diferenciado \\
\hline & indiferenciado \\
\hline \multirow[t]{2}{*}{ Profundidade da invasão } & até ss \\
\hline & além se \\
\hline \multirow[t]{2}{*}{ Comprometimento linfonodal } & ausente \\
\hline & presente \\
\hline \multirow[t]{2}{*}{ Metástase hepática } & ausente \\
\hline & presente \\
\hline \multirow[t]{2}{*}{ Metástase peritoneal } & ausente \\
\hline & presente \\
\hline \multirow[t]{2}{*}{ Estádio } & I II III \\
\hline & IV \\
\hline
\end{tabular}

ss: sub-serosa, se: serosa. 
Os quatro quimioterápicos estudados foram: mitomicina $\mathrm{C}$, doxorrubicina, cisplatina e 5-fluorouracil. A concentração final para cada quimioterápico foi de $10 \mu \mathrm{g} / \mathrm{ml}$ para mitomicina $\mathrm{C}$ e doxorrubicina, $25 \mu \mathrm{g} / \mathrm{ml}$ para a cisplatina e 50 $\mu \mathrm{g} / \mathrm{ml}$ para o 5-fluorouracil. Estas concentrações foram chamadas de concentrações de corte ${ }^{20}$ (cut off concentration), ou seja, as necessárias para se calcular o índice de inibição do quimioterápico.

Para este estudo, utilizaram-se somente 48 espaços da microplaca ou seja, seis linhas verticais de oito, divididas da seguinte forma:

1) grupo controle (continha somente meio de cultura); 2) grupo "branco" (continha meio de cultura, mas sem adição de reagente MTT na avaliação final); 3) grupo da mitomicina $\mathrm{C}$ (meio de cultura mais o quimioterápico na concentração de $10 \mu \mathrm{g} / \mathrm{ml}$ ); 4) grupo da doxorrubicina (meio de cultura mais o quimioterápico na concentração de $10 \mu \mathrm{g} / \mathrm{ml}$ ); 5) grupo da cisplatina (meio de cultura mais o quimioterápico na concentração de $25 \mu \mathrm{g} / \mathrm{ml}$ ); 6) grupo do 5-fluorouracil (meio de cultura mais o quimioterápico na concentração de $50 \mu \mathrm{g} / \mathrm{ml})$.

O volume total de cada espaço era de $200 \mu \mathrm{l}$. As placas foram submetidas a incubação por 48 horas, com $5 \%$ de gás carbônico a $37,5^{\circ} \mathrm{C}$. Após a incubação, a microplaca era centrifugada a 2.000 rotações por minuto e todo o meio de cultura e os quimioterápicos eram aspirados cuidadosamente, deixando-se no fundo as células tumorais. Utilizando-se a solução salina fosfatada lavava-se a microplaca e adicionava 20 $\mu l$ do reagente MTT por espaço. Este reagente interagia com as mitocôndrias das células tumorais viáveis, tornando as células de cor violeta. Após quatro horas, adicionavam-se $150 \mu \mathrm{l}$ de dimetil-sulfóxido (DMSO) por espaço da microplaca levando a liberação da coloração violeta pelas células, que então, era medido por densidade ótica. Através do aparelho de medição da densidade ótica ELx 800 ${ }^{\mathrm{TM}}$ (Automated microplate reader-Bio-Tek instruments inc.USA, 1995) no espectro de 540 a $630 \mathrm{~nm}$, foi realizada a leitura ótica das microplacas. A coloração mais densa correlacionava-se com maior número de células viáveis. Para leitura da densidade ótica foram utilizados espaços cujos valores variavam de 0,4 a 1,2. Os que não se incluíam nestes valores foram desprezados e se utilizou do programa de computador $\mathrm{KC}^{\mathrm{J}} \mathrm{Junior}^{\mathrm{TM}}$ (Bio-Tek instruments inc.USA, 1995). Através da fórmula A-B/A-C x 100 (\%), onde A era o valor da média da densidade ótica do grupo controle; $\mathrm{B}$, o valor da média da densidade ótica dos oito espaços de cada um dos quimioterápicos e $\mathrm{C}$ o valor da média da densidade ótica do grupo "branco", obtinha-se o índice de inibição, ou seja, o grau de inibição in vitro das células tumorais ${ }^{33}$.

Os resultados do teste MTT foram classificados como: - positivo ou sensível (células tumorais sensíveis à ação do quimioterápico) quando o grau de inibição era maior ou igual a 50\%; - negativo ou não sensível quando menor que $50 \%$.

Calculou-se o índice de atividade para cada quimioterápico, expresso em porcentagem através da fórmula do índice de inibição.

Os resultados do teste MTT foram comparados com a idade, sexo e aspectos microscópicos e estadiamento da neoplasia. Para comparação dos resultados do teste MTT com as características clínicas e anátomo-patológicas dos doentes, foi utilizado o teste do qui-quadrado $\left(\mathrm{X}^{2}\right)$. O nível de significância foi de $5 \%$.

\section{RESULTADOS}

Os resultados da avaliação da atividade in vitro através do teste MTT foram: $16,6 \%$ para a mitomicina $\mathrm{C}, 10 \%$ para a doxorrubicina, 6,6\% para a cisplatina e $6,6 \%$ para o 5fluorouracil (Tabela 2).

A comparação do teste MTT com os critérios das características clínicas e dos aspectos microscópicos e estádio do câncer gástrico demonstrou que as características como a idade, sexo, tipo histológico, profundidade do tumor, presença ou não de metástases linfonodais, hepática e peritonial e o estádio final, não tiveram relação estatística ( $p>0,05$ ) com o teste MTT (Tabela 3).

\section{DISCUSSÃO}

Os testes de químio-sensibilidade são considerados como métodos úteis para se estudar a atividade de agentes químioterápicos sobre células ou tecidos tumorais, após a sua resseção do trato gastrointestinal. Embora o seu potencial benefício, em termos de sobrevivência, ainda não esteja totalmente estabelecido, estes testes têm sido utilizados na prática clínica para direcionar a quimioterapia adjuvante na doença metastática ${ }^{29}$.

Os testes de químio-sensibilidade podem ser divididos em in vivo e in vitro, que são por sua vez subdivididos em clonogênicos e não clonogênicos ${ }^{14}$.

Nos testes in vivo são utilizados camundongos geneticamente modificados, especificamente preparados, de li-

Tabela 2 - Resultado da atividade in vitro dos quimioterápicos estudados pelo teste MTT.

\begin{tabular}{lccc}
\hline & $\begin{array}{c}\text { Quimioterápicos } \\
\text { Índice }\end{array}$ & $\begin{array}{c}\text { Concentração } \\
\text { final na placa }(\boldsymbol{\mu g} / \mathbf{m l})\end{array}$ & $\begin{array}{c}\text { Positividade } \\
\text { de atividade }(\boldsymbol{\%})\end{array}$ \\
\hline Mitomicina C & 10 & $5 / 30$ & 16,6 \\
Doxorrubicina & 10 & $3 / 30$ & 10,0 \\
Cisplatina & 25 & $2 / 30$ & 6,6 \\
5-Fluorouracil & 50 & $2 / 30$ & 6,6 \\
\hline
\end{tabular}

$\mu \mathrm{g} / \mathrm{ml}$ : micrograma por mililitro. 
Tabela 3 - Análise dos resultados do teste MTT com os aspectos clínicos e aspectos microscópicos e estádio do câncer gástrico (30 pacientes).

\begin{tabular}{|c|c|c|c|}
\hline Características & Positivo & $\begin{array}{l}\text { Teste MTT } \\
\text { Negativo }\end{array}$ & $\begin{array}{c}\text { Análise } \\
\text { Estatística }\end{array}$ \\
\hline Idade $>70$ anos & 3 & 3 & n.s. \\
\hline$=70$ anos & 5 & 19 & \\
\hline Sexo masculino & 4 & 13 & n.s. \\
\hline feminino & 4 & 9 & \\
\hline \multicolumn{4}{|c|}{ Diferenciação histológica } \\
\hline Diferenciado & 3 & 7 & n.s. \\
\hline Indiferenciado & 5 & 15 & \\
\hline \multicolumn{4}{|c|}{ Profundidade da invasão } \\
\hline Até ss & 3 & 4 & n.s. \\
\hline Além se & 5 & 18 & \\
\hline \multicolumn{4}{|c|}{ Comprometimento linfonodal } \\
\hline Ausente & 2 & 10 & n.s. \\
\hline Presente & 6 & 12 & \\
\hline \multicolumn{4}{|c|}{ Metástase hepática } \\
\hline Ausente & 8 & 21 & n.s. \\
\hline Presente & 0 & 1 & \\
\hline \multicolumn{4}{|c|}{ Metástase peritoneal } \\
\hline Ausente & 6 & 18 & n.s. \\
\hline Presente & 2 & 4 & \\
\hline Estádio I II III & 6 & 15 & n.s. \\
\hline IV & 2 & 7 & \\
\hline
\end{tabular}

ss: sub-serosa, se: serosa, n.s.: não significante $(p>0,05)$.

nhagem com ausência do timo, ou seja, sem linfócitos (linhagem BALB C Nu/Nu). Consistem na implantação de tumores humanos no tecido subcutâneo destes camundongos (também chamado de modelo xenográfico) e na aplicação de drogas quimioterápicas via intra-peritonial, observando-se há ou não regressão do tumor ${ }^{16}$.

A vantagem do teste in vivo, seria de que haveria a reprodução, em animais de experimento, da situação clínica, ou seja, permitiria a avaliação real da ação farmacodinâmica do agente quimioterápico ${ }^{16}$. Entretanto, os camundongos empregados são de custos elevados e difíceis de serem criados, o que torna o seu uso restrito a certos centros de pesquisa.

Os testes mais empregados são os in vitro. Iniciaram-se na década de 50 , foram modificados progressivamente e publicados na literatura ${ }^{10-28}$.

O teste MTT utilizado neste trabalho se baseia na viabilidade das células tumorais após cultura de 48 horas junto com os quimioterápicos estudados ${ }^{13}$. É colocado reagente colorimétrico MTT que reage através da redução do sal tetrazolato, pela enzima deidrogenase succínica, presente na mitocôndria da célula tumoral, o qual adquire uma coloração violácea e esta é avaliada pela espectrofotometria. Este método é de fácil manuseio, custo relativamente baixo, permitindo resultados em 48 horas, razão pela qual foi utilizado neste estudo.

A concentração de corte ( cut off concentration) utilizada na placa de cultura para se calcular o índice de inibição das células tumorais aos agentes quimioterápicos estudados, foi determinada comparando-se a inibição do crescimento tumoral do método in vivo (modelo xenográfico) com o teste in vitro. Portanto, do modelo in vivo se obtém o grau de inibição comparando grupo controle $(\mathrm{C})$ e grupo tratado $(\mathrm{T})$, ou seja, o índice $\mathrm{T} / \mathrm{C}$ em porcentagem e do modelo in vitro se obtém o grau de inibição com cálculo da concentração inibitória 50 ( $\left(\mathrm{IC}_{50}\right) \mathrm{em} \mu \mathrm{g} /$ $\mathrm{ml}$ para cada quimioterápico. Correlacionando os dois métodos, obteve-se a concentração de corte ${ }^{26}$.

Neste estudo, foram testados quatro quimioterápicos in vitro, isoladamente, quais sejam, mitomicina $\mathrm{C}$ e doxorrubicina, ambas na concentração de $10 \mu \mathrm{g} / \mathrm{ml}$, cisplatina em $25 \mu \mathrm{g} / \mathrm{ml}$ e 5 -fluorouracil em $50 \mu \mathrm{g} / \mathrm{ml}$. Os resultados obtidos mostraram que os quimioterápicos tiveram pouca ação sobre células tumorais e que variou neste estudo de $6,6 \%$ a $16,6 \%$. Estes resultados foram semelhantes aos resultados obtidos em doentes japoneses ${ }^{23}$ (Tabela 4).

O teste MTT parece ser útil na avaliação do efeito citotóxico de agentes quimioterápicos, cuja eficiência não dependam do período de incubação como é o caso, quando se avaliam a mitomicina $\mathrm{C}$, a doxorrubicina e a cisplatina ${ }^{21-22}$.

$\mathrm{O}$ índice de atividade sobre células tumorais do 5fluorouracil foi baixa $(6,6 \%)$. Este resultado pode estar relacionado ao curto período de contato do quimioterápico com as células tumorais (48 horas) usado no teste $\mathrm{MTT}^{24,27}$. Portanto para se melhor avaliar a químio-sensibilidade in vitro do 5 fluororuracil, seria necessário maior tempo de incubação, tendo-se como opção o teste HDRA que apresentou índices de atividade em torno de $18 \%{ }^{21}$.

A comparação do teste MTT com as características clínicas e aspectos microscópicos e estádio da neoplasia de- 
Tabela 4 - Resultado da atividade in vitro dos quimioterápicos estudados pelo teste MTT em 112 doentes da experiência japonesa.

\begin{tabular}{lccc}
\hline & $\begin{array}{c}\text { Quimioterápicos } \\
\text { Índice }\end{array}$ & $\begin{array}{c}\text { Concentração } \\
\text { final na placa }(\boldsymbol{\mu g} / \mathbf{m l})\end{array}$ & $\begin{array}{c}\text { Positividade } \\
\text { de atividade }(\%)\end{array}$ \\
\hline Mitomicina C & 10 & $15 / 112$ & 13,4 \\
Doxorrubicina & 10 & $14 / 112$ & 12,5 \\
Cisplatina & 25 & $7 / 112$ & 6,3 \\
5-Fluorouracil & 50 & $6 / 112$ & 5,4 \\
\hline
\end{tabular}

$\mu \mathrm{g} / \mathrm{ml}$ : micrograma por mililitro.

Fonte: Matsuzaki WS. Valor de teste de quimio-sensibilidade para escolha da terapêtica quimioterápica no câncer gástrico avançado. Dissertação (Mestrado). São Paulo: Faculdade de Medicina, Universidade de São Paulo; 2001.

monstraram que a químio-sensibilidade não teve correlação com a idade, sexo e aspectos microscópicos e estádio.

Estes resultados foram semelhantes aos dados obtidos em doentes japoneses ${ }^{29}$, porém diferiu em apenas uma análise no qual houve evidência na correlação com o tipo histológico indiferenciado (Tabela 5).

$\mathrm{O}$ atual estudo, apesar da casuística pequena confirma dados da literatura, onde se demonstra pouca relação entre diferenciação histológica e químio-sensibilidade ${ }^{24,28}$.

Apesar da limitações in vitro de poder refletir o real valor da eficácia clínica dos agentes quimioterápicos, o uso de testes de químio-sensibilidade se mostram úteis na seleção da quimioterapia na prática clínica ${ }^{31,32,35}$.
Os resultados obtidos nas condições de execução do presente trabalho, em 30 doentes com câncer gástrico, permitem concluir que: 1 . a introdução e a familiarização do uso do teste MTT em nosso meio poderá criar um fator preditivo na seleção das drogas e conseqüentemente dos doentes considerados susceptíveis à quimioterapia, 2. a análise dos resultados do teste MTT demonstrou que a ação dos quimioterápicos estudados sobre células tumorais do câncer gástrico é baixa $(6,6 \%$ a 16,6\%), 3. os resultados da ação dos quimioterápicos in vitro não apresentou relação estatística com a idade, sexo, aspectos microscópicos e estádio destes doentes, 4. utilizando a mesma metodologia, tanto em nosso meio como em pacientes japoneses, a quimio-sensibilidade se

Tabela 5 - Análise dos resultados do Teste MTT com os aspectos clínicos e características anátomo-patológicas do câncer gástrico em 112 doentes da experiência japonesa.

\begin{tabular}{|c|c|c|c|}
\hline Características & Positivo & $\begin{array}{l}\text { Teste MTT } \\
\text { Negativo }\end{array}$ & $\begin{array}{c}\text { Análise } \\
\text { Estatística }\end{array}$ \\
\hline Idade $>70$ anos & 14 & 68 & n.s. \\
\hline$\leq 70$ anos & 8 & 22 & \\
\hline Sexo masculino & 18 & 65 & n.s. \\
\hline feminino & 4 & 25 & \\
\hline \multicolumn{4}{|c|}{ Diferenciação histológica } \\
\hline Diferenciado & 15 & 25 & $\mathrm{p}<0,05$. \\
\hline Indiferenciado & 7 & 65 & \\
\hline \multicolumn{4}{|c|}{ Profundidade da invasão } \\
\hline Até ss & 6 & 38 & n.s. \\
\hline Além se & 16 & 52 & \\
\hline \multicolumn{4}{|c|}{ Comprometimento linfonodal } \\
\hline Ausente & 4 & 21 & n.s. \\
\hline Presente & 18 & 69 & \\
\hline \multicolumn{4}{|c|}{ Metástase hepática } \\
\hline Ausente & 20 & 82 & n.s. \\
\hline Presente & 2 & 8 & \\
\hline \multicolumn{4}{|c|}{ Metástase peritoneal } \\
\hline Ausente & 18 & 75 & n.s. \\
\hline Presente & 4 & 15 & \\
\hline Estádio I II III & 15 & 55 & n.s. \\
\hline IV & 7 & 35 & \\
\hline
\end{tabular}

ss: sub-serosa, se: serosa, n.s.: não significante estatisticamente, $p<0,05$ significante.

Fonte: Matsuzaki WS. Valor de teste de quimio-sensibilidade para escolha da terapêutica quimioterápica no câncer gástrico avançado. Dissertação (Mestrado). São Paulo: Faculdade de Medicina, Universidade de São Paulo; 2001. 
mostrou baixa em ambos os estudos, podendo-se deduzir que os resultados da químio-sensibilidade também independem da etnia.

\section{AGRADECIMENTOS}

À Faculdade de Ciências Médicas da Santa Casa de São Paulo (FCMSCSP) e à Irmandade da Santa Casa de Mise- ricórdia de São Paulo, pela oportunidade de poder realizar este trabalho de tese de Doutorado e pelo aperfeiçoamento científico que esta conceituada Instituição continuamente oferece. À Coordenadoria de Aperfeiçoamento de Pessoal de Nível Superior (CAPES), pelo auxílio financeiro.

Ao Fundo de Amparo à Pesquisa (FAP) da Fundação Arnaldo Vieira de Carvalho da FCMSCSP, sem a qual não seria possível a realização desta pesquisa.

\begin{abstract}
Background: Utilizing the MTT chemosensitivity test to evaluated the action of chemotherapeutic agents on cancer cells of 30 patients with advanced gastric cancer who underwent surgical treatment. Correlation between test results, clinical and anatomopathological aspects, disease staging, were dane using the same methodology of study performed in Japanese patients presented in master dissertation. Methods: MTT test was carried out in cancer cells of 30 patients with gastric adenocarcinoma submitted to surgical treatment in the Department of Surgery at Santa Casa de São Paulo, Medical School. The following drugs were studied in vitro: mitomycin C, doxorubicin, cisplatin and 5-fluorouracil. Results: Efficacy rates on tumors cells were reported as being: $16.6 \%$ for mitomycin $C, 10.0 \%$ for doxorubicin, $6.6 \%$ for cisplatin and $6.6 \%$ for 5 -fluorouracil. There were no statistically significant correlations between chemosensitivity and age, sex, microscopic aspect and disease staging $(p>0.05)$. Conclusion: The effect of the studied chemotherapeutical drugs on gastric cancer cell cultivated in vitro is low. The results of chemotherapy effect in vitro proved no statistical correlation with age, sex, microscopic aspect and disease staging of these patients. Using the same methodology in our patients (non oriental) or in Japanese patients the chemosensitivity was low in both studies. We can conclude that no matter which race is studied it will get the same low response results of chemosensitivity. With development of new chemotherapeutics agents the expectation is greater for better results in clinical practice. With the utilization and the spread of the MTT chemosensitivity test in our patients it will be possible to create protocols and multicentric studies for selection of new chemotherapeutic agents.
\end{abstract}

Key words: Stomach Neoplasms; Chemotherapy, adjuvant; Adenocarcinoma; Drug screening assays, antitumor.

\section{REFERÊNCIAS}

1. Brasil. Ministério da Saúde. Instituto Nacional do Câncer-INCA. Estimativas da incidência e mortalidade por câncer no Brasil, 2005. Rio de Janeiro; 2005.

2. Plummer M, Franceschi S, Munoz N. Epidemiology of gastric cancer. IARC Sci Publ. 2004;(157):311-26.

3. Terry MB, Gaudet MM, Gammon MD. The epidemiology of gastric cancer. Semin Radiat Oncol. 2002;12(2):111-27.

4. Lambert R, Guilloux A, Oshima A, Pompe-Kirn V, Bray F, Parkin $\mathrm{M}$, Ajiki W, Tsukuma H. Incidence and mortality from stomach cancer in Japan, Slovenia and the USA. Int J Cancer. 2002;97(6):811-8.

5. Kobayashi T, Kikuchi S, Lin Y, Yagyu K, Obata Y, Ogihara A, Hasegawa A, Miki K, Kaneko E, Mizukoshi H, Sakiyama T, Tenjin H. Trends in the incidence of gastric cancer in Japan and their associations with Helicobacter pylori infection and gastric mucosal atrophy. Gastric Cancer. 2004;7(4):233-9.

6. Kim JP, Kim YW, Yang HK, Noh DY. Significant prognostic factors by multivariate analysis of 3926 gastric cancer patients. World J Surg. 1994;18(6):872-7; discussion 877-8.

7. Janunger KG, Hafstrom L, Glimelius B. Chemotherapy in gastric cancer: a review and updated meta-analysis. Eur J Surg. 2002;168(11):597-608.

8. Sakamoto J, Morita S, Kodera Y, Rahman M, Nakao A. Adjuvant chemotherapy for gastric cancer in Japan: global and Japanese perspectives. Cancer Chemother Pharmacol. 2004; 54(suppl1):S25-31.

9. Karpeh MS, Kelsen DP, Tepper JE. Cancer of the stomach. In: De Vitta VT, Hellmann MD, Rosenberg SA, editors. Cancer.
Principles and practice of oncology. $6^{\text {th }}$ ed. Philadelphia: Lippincot Williams \& Wilkins; 2001. p.1092-125.

10. Black MM, Speer FD. Further observations on the effects of cancer chemotherapeutic agents on the in vitro dehydrogenase activity of cancer tissue. J Natl Cancer Inst. 1954;14(5):1147-58.

11. Wright JC, Cobb JP, Gumport SL, Golomb FM, Safadi D. Investigation of the relation between clinical and tissue-culture response to chemotherapeutic agents on human cancer. N Engl J Med. 1957;257(25):1207-11.

12. Hamburger AW, Salmon SE. Primary bioassay of human tumor stem cells. Science. 177;97(4302):461-3.

13. Mosmann T. Rapid colorimetric assay for cellular growth and survival: application to proliferation and cytotoxicity assays. J Immunol Methods. 1983; 65(1-2):55-63.

14. Weisenthal LM, Lippman ME. Clonogenic and nonclonogenic in vitro chemosensitivity assays. Cancer Treat Rep. 1985;69(6):615-32.

15. Cole SP. Rapid chemosensitivity testing of human lung tumor cells using the MTT assay. Cancer Chemother Pharmacol. 1986;17(3):259-63.

16. Shimoyama Y, Kubota T, Watanabe M, Ishibiki K, Abe O. Predictability of in vivo chemosensitivity by in vitro MTT assay with reference for clonogenic assay. J Surg Oncol. 1989;4(1):12-8.

17. Suto A, Kubota T, Shimoyama Y, Ishibiki K, Abe O. MTT assay with reference to the clinical effect of chemotherapy. J Surg Oncol. 1989;42(1):28-32.

18. Furukawa T, Kubota T, Suto A, Takahara T, Yamaguchi H, Takeuchi T, Kase S, Kodaira S, Ishibiki K, Kitajima M. Clinical usefulness of chemosensitivity testing using the MTT assay. J Surg Oncol. 1991;48(3):188-93. 
19. Hoffman RM. Three-dimensional histoculture: origins and applications in cancer research. Cancer Cells. 1991;3(3):86-92.

20. Hoffman RM. In vitro assays for chemotherapy sensitivity. Crit Rev Oncol Hematol. 1993;15(2):99-111.

21. Furukawa T, Kubota T, Hoffman RM. Clinical applications of the histoculture drug response assay. Clin Cancer Res. 1995;1(3):305-11.

22. Kubota T, Sasano N, Abe O, Nakao I, Kawamura E, Saito T,Endo M, Kimura K, Demura H, Sasano H, Nagura H, Ogawa Nand Hoffman RM. Chemosensitivity study group for the histoculture drug-response assay. Potential of the histoculture drug-response assay to contribute to cancer patient survival. Clin Cancer Res. 1995;1(12):1537-43.

23. Inaba M, Tashiro T, Sato S, Ohnishi Y, Tanisaka K, Kobayashi $\mathrm{H}$, Koezuka M. In vitro-in vivo correlation in anticancer drug sensitivity test using AUC-based concentrations and collagen gel droplet-embedded culture. Oncology. 1996; 53(3):250-7.

24. Saikawa Y, Kubota T, Furukawa T, Suto A, Watanabe M, Kumai K, Ishibiki K, Kitajima M. Single-cell suspension assay with MTT endpoint is useful for evaluating the optimal adjuvant chemotherapy for advanced gastric cancer. Jpn J Cancer Res. 1994;85(7):762-5.

25. Yamaue H, Tanimura H, Nakamori M, Noguchi K, Iwahashi M, Tani M, Hotta T, Murakami K, Ishimoto K. Clinical evaluation of chemosensitivity testing for patients with colorectal cancer using MTT assay. Dis Colon Rectum. 1996;39(4):416-22.

26. Kubota T, Otani Y, Watanabe M, Kitajima M. [Clinical criteria of chemosensitivity test]. Nippon Rinsho. 1997;55(5):1050-3.

27. Fujita K, Kubota T, Matsuzaki SW, Otani Y, Watanabe M, Teramoto T, Kumai K, Kitajima M. Further evidence for the value of chemosensitivit test in deciding appropriate chemotherapy for advanced gastric cancer. Anticancer Res. 1998; 18(3B):1973-8.

28. Abe S, Kubota T, Matsuzaki SW, Otani Y, Watanabe M, Teramoto T, Kumai K, Kitajima M. Chemosensitivity test is useful in evaluating the appropriate adjuvant cancer chemotherapy for stage III non-scirrhous and scirrhous gastric cancers. Anticancer Res. 1999;19(5C):4581-6.
29. Matsuzaki WS. Valor de teste de quimio-sensibilidade para escolha da terapêutica quimioterápica no câncer gástrico avançado [dissertação]. São Paulo (SP): Universidade de São Paulo; 2001.

30. Kabeshima Y, Kubota T, Watanabe M, Hasegawa H, Furukawa T, Kitajima M. Clinical usefulness of chemosensitivity test for advanced colorectal cancer. Anticancer Res. 2002;22(5):3033-7.

31. Kubota T, Otani Y, Furukawa T, Hasegawa H, Watanabe M, Kitajima M. Chemosensitivity testing — present and future in Japan. Recent Results Cancer Res. 2003;161:231-41.

32. Kubota T, Egawa T, Otani Y, Furukawa T, Saikawa Y, Yoshida M, Watanabe M, Kumai K, Kitajima M. Cancer chemotherapy chemosensitivity testing is useful in evaluating the appropriate adjuvant cancer chemotherapy for stages III/IV gastric cancer without peritoneal dissemination. Anticancer Res. 2003;23(1B):583-7.

33. Sargent JM. The use of the MTT assay to study drug resistance in fresh tumour samples. Recent Results Cancer Res. 2003;161:13-25.

34. Nishi M, Omori Y, Miwa K, editors. Japanese classification of gastric carcinoma. Japanese Research Society for Gastric Cancer (JRSGC). $1^{\text {st }}$ English edition. Tokyo: Kanehara \& Co;1995.

35. Kim R, Emi M, Tanabe K, Uchida Y, Toge T. Chemosensitivity testing for gastrointestinal cancer: survival benefit potential and limitations. Anticancer Drugs. 2003;14(9):715-23.

Como citar este artigo:

Matsuzaki WS, Rodrigues FCM, Malheiros CA, Rahal F. Uso de teste de químio-sensibilidade para escolha da quimioterapia adjuvante no câncer gástrico avançado. Rev Col Bras Cir. [periódico na Internet] 2006 Jul-Ago;33(4). Disponível em URL: www.scielo.br/rcbc

Endereço para correspondência:

Francisco César Martins Rodrigues

Alameda Áustria, 128

Alphaville Residencial 1

06474-270 - Barueri - SP 